UDC 341.33

LBC 67.5

\title{
REMEDIES AND METHODS OF PROTECTING JOURNALISTS IN INTERNATIONAL HUMANITARIAN LAW
}

\author{
Hasson Dhiyaa Hasson \\ Peoples' Friendship University of Russia (RUDN - University), Moscow, Russian Federation \\ Evgeny V. Martynenko \\ Peoples' Friendship University of Russia (RUDN - University), Moscow, Russian Federation
}

Introduction: in this article the author analyzes the acts of international humanitarian law pertaining to the protection of journalists performing their professional duties under the conditions of armed conflicts. It is telling that international humanitarian law provides significantly fewer guarantees of protection for journalists in the course of a non-international armed conflict, which is due to the problem of the defense of the state sovereignty. The lack of the clear criteria for the identification of a non-international armed conflict, minimum guarantees of the rights of mass media professionals in such circumstances allow the parties to manipulate the status of the situation and to set fewer guarantees than those provided for international conflicts. The assessment of the statistical data indicates a significant violation of the rights of journalists in the countries where there are non-international armed conflicts. On the basis of the statistical data the author draws a conclusion on the low effectiveness of the existing law and the need to continue the work on the improvement of legal norms, and remedies and methods of protection of journalists performing their professional duties. Methods: the methodological basis of the article is formed by a set of scientific methods such as the method of analysis and synthesis as the main methods, the method of interpretation of law and formal legal method.

Results: the study has proved that in all justification of the division of armed conflicts into international and non-international ones, this approach complicates the practical application of the legal rules, does not allow to provide journalists with an equal extent of guarantees, and does not meet the modern world realities not to differentiate different types of conflicts.

Conclusions: as a result of the study the author has proposed extending the domain of international humanitarian law to the situation of intense internal armed conflicts, to enshrine in legislation the compulsory guaranteed minimum of rights of journalists performing their duties in armed conflicts, regardless of their type, and to create a post of Special Representative of the UN Secretary General for the safety of journalists.

Keywords: international humanitarian law, protection of journalists, guarantees of protection of journalists, violations of the rights of journalists, international and non-international armed conflicts, Geneva Convention, effective regulations.

\section{СРЕДСТВА И МЕТОДЫ ЗАЩИТЫ ЖУРНАЛИСТОВ В МЕЖДУНАРОДНОМ ГУМАНИТАРНОМ ПРАВЕ}

\author{
Хассон Дия Хассон \\ Российский университет дружбы народов, г. Москва, Российская Федерация \\ Евгений Владимирович Мартыненко \\ Российский университет дружбы народов, г. Москва, Российская Федерация
}

Введение: в представленной статье авторы анализируют акты международного гуманитарного права, посвященные обеспечению защиты журналистов, осуществляющих профессиональную деятельность в ус- 
ловиях вооруженных конфликтов. Показательно, что международное гуманитарное право предусматривает значительно меньше гарантий для журналистов в период немеждународного вооруженного конфликта, что обусловлено проблемой защиты государственного суверенитета. Отсутствие четких критериев идентификации немеждународного вооруженного конфликта, минимальные гарантии прав сотрудников средств массовой информации в таких условиях позволяют сторонам манипулировать статусом ситуации и устанавливать меньшие гарантии в сравнении с предусмотренными для конфликтов международного характера. Оценка статистических данных свидетельствует о значительных нарушениях прав журналистов в странах, на территории которых наблюдаются вооруженные конфликты немеждународного характера. На основании статистических данных автор делает вывод о низкой эффективности существующих норм права и о необходимости продолжить работу по совершенствованию правовых норм, средств и методов защиты журналистов при выполнении ими своей профессиональной деятельности.

Методы: методологическая основа настоящей статьи формируется совокупностью методов научного познания, среди которых - метод синтеза и анализа как основные общенаучные методы, метод толкования права и формально-юридический метод.

Результаты: исследование показало, что при всей оправданности разделения вооруженных конфликтов на международные и немеждународные, такой подход усложняет практическое применение правовых норм, не позволяет предоставить равный объем гарантий журналистам, не отвечает современным реалиям стирания границ между различными видами конфликтов.

Выводы: в результате проведенного исследования предложено расширить сферу действия норм международного гуманитарного права на ситуацию интенсивных внутренних вооруженных конфликтов, зафиксировать обязательный гарантированный минимум прав журналистов при выполнении ими служебных обязанностей в условиях вооруженных конфликтов независимо от их вида, а также учредить должность Специального представителя Генерального секретаря ООН по безопасности журналистов.

Ключевые слова: международное гуманитарное право, защита журналистов, гарантии защиты журналистов, нарушения прав журналистов, вооруженные конфликты международного и немеждународного характера, Женевские конвенции, эффективные правовые нормы.

\section{Введение}

Актуальность исследования проблематики, связанной с обеспечением защиты прав журналистов, которые осуществляют свои обязанности в экстремальных условиях, в том числе в условиях вооруженных конфликтов, в настоящее время трудно переоценить, при этом в современной юридической науке данной теме уделяется неоправданно малое внимание. Нарастание международной напряженности, столкновение интересов мировых держав приводят к увеличению числа локальных вооруженных столкновений. Информационная война последние годы является частью войны гибридной, в связи с чем несмотря на активную работу международных и профессиональных правозащитных организаций участились сообщения о правонарушениях и преступлениях, совершенных в отношении работающих в зоне конфликтов журналистов и иных работников средств массовой информации.

Деятельность репортеров в период активных вооруженных столкновений осложняется определенными ограничениями, направленными на обеспечение минимального дос- тупа к определенной информации. В числе таких ограничений - введение комендантского часа, обязательное введение специальных документов и удостоверений, подтверждающих статус работника СМИ. В таких условиях может быть осложнено не только непосредственное ведение профессиональной деятельности журналиста, но и применение норм и гарантий международного гуманитарного права для защиты его как гражданского лица.

Положениями Женевских конвенций 1949 г. предусмотрено разделение вооруженных конфликтов на два основных типа: военные конфликты немеждународного и международного характера [10, с. 129-134]. При этом границы определения военного конфликта, особенно для первого типа, четко не зафиксированы, что позволяет манипулировать статусом конфликта, в том числе и для ограничения прав журналистов.

Применение норм и гарантий защиты для данных типов вооруженных столкновений в рамках международного гуманитарного права дифференцировано. Если в ситуации вооруженных конфликтов международного характера предполагается предоставление репор- 


\section{МЕЖДУНАРОДНОЕ ПРАВО И СРАВНИТЕЛЬНОЕ ПРАВОВЕДЕНИЕ}

терам и сотрудникам средств массовой информации максимального объема гарантий и прав на защиту как гражданских лиц, то в ситуации немеждународных конфликтов такие гарантии и право на защиту определенным образом ограничены. Помимо этого современное международное гуманитарное право предусматривает различный объем правовых гарантий по обеспечению безопасности в отношении прикомандированных, аккредитованных журналистов и независимых, не прикомандированных ни к одной из сторон конфликта, репортеров [18, p. 29-31]. В частности, для таких сотрудников средств массовой информации, которыми чаще всего являются репортеры-фрилансеры, сотрудники независимых и интернет-СМИ, праву на защиту не корреспондирует обязанность военных определенной стороны конфликта по их защите, в то время как для аккредитованных журналистов обязанность по обеспечению безопасности предусмотрена. Такие нормы закрепляют по отношению к безопасности репортеров, не прикомандированных и не аккредитованных ни одной из сторон, ситуацию полного игнорирования в правовом поле, независимо от уровня риска для жизни, связанного с их профессиональной деятельностью, и объективной угрозы нарушения прав. По нашему мнению, такая ситуация является дискриминационной в контексте единства гарантий прав безопасности журналистов независимо от их принадлежности и прикомандирования к одному из участников конфликта, независимо от профессионального статуса, гражданства, позиции по отношению к конфликту и профессионального статуса.

Согласно нормам международного гуманитарного права журналисты не имеют особого статуса и приравниваются к гражданскому населению по объему гарантий защиты, в том числе:

- они не могут являться объектом нападения ни одной из сторон-участниц конфликта (п. 2 ст. 51 Протокола I);

- они обладают правом на уважительное отношение к их собственности, кроме случаев, когда эта собственность может быть использована в военных целях или имеет военный характер (ст. 52 Протокола I);

- предумышленное нападение, послужившее причиной серьезного телесного повреж- дения или смерти, относится к военным преступлениям (ст. 85 Протокола I) [8, с. 43].

Наделение журналистов правовым статусом гражданского лица позволяет им пользоваться всеми предусмотренными для таких лиц гарантиями защиты и обеспечения безопасности, что также распространяется на ситуацию задержания или пленения журналиста.

\section{Классификация пределов защиты прав журналистов}

Нормами международного гуманитарного права, несмотря на установленные гарантии, предусмотрены и определенные возможности по их ограничению, что отражается в категории пределов защиты. Они могут быть классифицированы по различным критериям. Одним из примеров является их деление на объективные и субъективные. Согласно другой классификации пределы защиты могут предусматривать ситуации, когда журналист утрачивает только фактическую защиту или фактическую защиту в совокупности с правом на ее предоставление. К первой группе можно отнести ситуации, когда журналист находится внутри военного объекта или использует в качестве одежды военную форму. Здесь стороны конфликта не имеют объективной возможности распознать журналиста как лицо, которому согласно нормам международного права предоставляется статус представителя гражданского населения, в связи с чем утрачивается фактическая защита. В другом случае, например, при осуществлении разведки или использовании вооружения для участия в конфликте сотрудник средств массовой информации утрачивает право на защиту в соответствии с нормами международного гуманитарного права, определяющими подобные действия журналиста как основания для утраты им соответствующего статуса. Необходимо отметить, что международные договоры и конвенции не закрепляют объективных норм идентификации журналиста, хотя таковыми могут являться, например, наличие специального знака отличия прессы или удостоверения журналиста, а также прочие признаки, позволяющие довольно точно идентифицировать профессиональный статус сотрудни- 
ка средств массовой информации. Неоднократно эксперты и ученые выдвигали предложение о необходимости определения единого специального знака, который должен отличать журналиста от иных лиц в условиях боевых действий, однако единого мнения о целесообразности такого решения не выработалось [4]. Представляется, что распространение отличительного символа не сможет решить проблему обеспечения безопасности журналистов, так как в экстремальной ситуации он может забыть его закрепить, знак может получить повреждения и пр.

Журналист может фактически утрачивать возможность защиты при приближении к военным объектам или местам активных вооруженных столкновений на опасное расстояние, при непосредственном нахождении внутри вооруженного формирования, когда противник фактически не имеет возможность отличить сотрудника средств массовой информации от комбатанта [7, с. 273-274]. В данном контексте можно выделить три основных проблемных аспекта:

Во-первых, необходимо установить максимум расстояния, при котором журналист утрачивает правовые гарантии защиты. Очевидно, что нахождение его внутри военного объекта ведет к повышению уровня риска гибели, повреждения его имущества, потому что противник лишен объективной возможности идентифицировать журналиста и предоставить ему соответствующие гарантии.

Во-вторых, значительное влияние оказывает характер нападения одной из сторон конфликта на военный объект. Так, при стремительной атаке, атаке с воздуха возможность идентифицировать журналиста и предоставить ему гарантии защиты отсутствует. Если характер нападения позволяет определить журналиста и отличить его от комбатантов, то фактическая защита его должна продолжаться и обеспечиваться соответствующими гарантиями нападающей стороны.

B-третьих, нормы международного гуманитарного права не предусматривают предоставление специальных гарантий сотруднику средств массовой информации, находящемуся в непосредственной близости от военного объекта, при его пленении противником, и не позволяет осуществлять его защиту в усло- виях плена. По нашему мнению, данные нормы должны быть уточнены, а журналисту, захваченному вблизи военного объекта, должен предоставляться статус военнопленного.

Международная деятельность по обеспечению защиты прав журналистов в вооруженных конфликтах в разных странах, разработка предложений по совершенствованию гарантий прав журналистов и механизма их обеспечения, совершенствование правового регулирования участия сотрудников средств массовой информации осуществляются при активном участии международных организаций. Так, среди подразделений $\mathrm{OOH}$ данная проблематика входит в спектр функций Комитета по защите журналистов и ряда других органов, в том числе ЮНОПС и ЮНЕСКО. Осознавая значимость в современном мире проблемы обеспечения свободы слова и выражения мнения независимо от обстоятельств, $\mathrm{OOH}$ приняла ряд дополняющих резолюцию № 1738 Совета Безопасности документов, которые посвящены решению проблемы безнаказанности виновных в нарушениях прав журналистов в условиях вооруженных конфликтов, как международных, так и немеждународных. Еще одной вехой, обозначившей озабоченность $\mathrm{OOH}$ проблемой защиты сотрудников средств массовой информации, стало принятие в 2012 г. Плана действий ООН по обеспечению безопасности журналистов, в том числе и в районах международных конфликтов [2, с. 82]. В рамках Плана предусмотрен ряд мероприятий, предполагающих создание и функционирование на регулярной основе специальных комиссий по расследованию фактов нарушения прав и случаев убийств журналистов, а также иные направления оптимизации правоприменительного механизма предоставления соответствующих гарантий и обеспечения условий для реализации во всем мире права на свободу выражения мнения и свободу слова. По нашему мнению, несмотря на возросшую активность ООН предпринимаемые международным сообществом усилия следует признать минимальными. Их недостаточность подтверждается статистическими данными, иллюстрирующими зафиксированные в зонах вооруженных конфликтов случаи нарушения прав журналистов и их гибели. 


\section{МЕЖДУНАРОДНОЕ ПРАВО И СРАВНИТЕЛЬНОЕ ПРАВОВЕДЕНИЕ}

Следует отметить, что в последние годы участились случаи столкновений, которые можно отнести к немеждународным вооруженным конфликтам. Длительное время данные конфликты исключались из зоны регулирования международного гуманитарного права. Включение их в правовое поле связано с принятием Женевских конвенций 1949 г., одна из общих статей которых обязывала государства согласиться на ограничение насилия в немеждународных конфликтах с применением оружия. Фундаментальное значение данной нормы отразилось в общепринятом сегодня названии третьей общей статьи - «Мини-конвенция». Тем не менее ее положения были несовершенны и ограничены, они устанавливали минимальные гарантии для мирного населения и иных участников немеждународных военных конфликтов. Так, отсутствовали указания на порядок обеспечения защиты мирных жителей от единичных и массовых репрессий, отношения к имуществу сторон конфликта и лиц, не принимающих в нем активного участия, не урегулированными оказались и прочие сферы.

Правовая защита населения была усилена Первым и Вторым Дополнительными Протоколами, принятыми в 1977 г., которые усилили гарантии защиты в общем всего гражданского населения, а также определили минимум гарантий правовой защиты для иных лиц, не пользующихся более благоприятным режимом защиты $[1$, с. 408-417]. Усложняет обеспечение единых гарантий защиты прав журналистов, осуществляющих свою деятельность в зоне немеждународного вооруженного конфликта, отсутствие четких критериев, которые позволяют идентифицировать данный тип конфликта. Здесь следует привести мнение И.И. Котлярова, основанное на отнесении к данному понятию ситуаций вооруженных столкновений между негосударственными (неправительственными) вооруженными группами и государственными вооруженными силами государства $[6$, с. 55].

В последние десятилетия неоднократно прилагались определенные усилия по устранению различий между вооруженными конфликтами немеждународного и международного характера для формирования общего свода норм международного гуманитарного права, позволяющего рассматривать все ситуации вооруженных столкновений. Несмотря на то что данные усилия не увенчались полным успехом, постепенное формирование международной практики, определенные изменения в прецедентном праве способствуют де-факто стиранию грани между этими двумя видами.

Размытиеграниц между общепризнанными видами конфликтов особенно актуально сегодня, когда в течении и разрешении многих внутренних военных конфликтов активно участвуют внешние акторы, преследующие в таких ситуациях собственные геополитические цели. Следствием этого является применение более строгих гарантий защиты, предусмотренных ранее только для международных вооруженных противостояний или только для строго формально определяемых в Протоколе II вооруженных конфликтов немеждународного характера, сегодня все чаще применяются к интерпретации событий даже категории конфликтов, определяемой в общей статье 3 . Решить обозначенные проблемы международные организации пытаются и в рамках развития международного права прав человека, в том числе за счет судебных прецедентов и добавления новых гарантий защиты прав человека [13, с. 172-178] в условиях конфликтов независимо от их характеристик.

Конфликты немеждународного характеpa, в том числе за счет заинтересованности в их определенном исходе внешних акторов, становятся все более интенсивными. Об этом свидетельствуют увеличение числа миссий $\mathrm{OOH}$ по поддержанию мира и формирование международных коалиций для оказания помощи какому-либо государству, на территории которого происходит противостояние между правительственными войсками и организованными негосударственными вооруженными группами. Сочетание отмеченных характеристик современных немеждународных конфликтов усложняет проведение свойственной международному гуманитарному праву границы между вооруженными конфликтами различных типов [5; 12].

Одной из наиболее важных для защиты журналистов в условиях немеждународных вооруженных столкновений является проблема территориальных границ применения норм международного гуманитарного права, кото- 
рая напрямую положениями Конвенций не урегулирована. Для ее разрешения Международный уголовный трибунал по бывшей Югославии указал, что некоторые положения необходимо применять не только в районе фактических военных действий, но и на всей территории, контролируемой участниками конфликта вплоть до момента его официального урегулирования. В число данных положений, не ограничиваемых территориально, включены и те, «которые относятся к регулированию защиты гражданских лиц и военнопленных» [16]. Это позволяет распространить правовой статус журналистов как гражданских лиц, предусмотренное право на защиту и его гарантии в рамках международного гуманитарного права на сотрудников средств массовой информации, действующих на всей территории государства, в котором возник внутренний вооруженный конфликт.

\section{Заключение}

В заключение статьи можно сделать вывод о том, что нормы международного гуманитарного права предусматривают меньший объем гарантий для журналистов, осуществляющих свою профессиональную деятельность в условиях немеждународных вооруженных конфликтов. Такая ситуация обусловлена в первую очередь необходимостью защиты государственного суверенитета. При всей объективности деления конфликтов на немеждународные и международные в практическом плане оно не совсем оправдано и удобно. Закрепление такого деления позволяет заинтересованным сторонам манипулировать статусом внутренних конфликтов и не предоставлять предусмотренные международным гуманитарным правом гарантии защиты прав журналистов. Такой подход со всей очевидностью следует признать неудобным для практического применения, особенно в контексте распространения гибридных войн и внутренних вооруженных конфликтов, течение которых предопределено косвенным участием и заинтересованностью внешних акторов. События последних лет подтверждают, что все большее число вооруженных столкновений, которые с формальной точки зрения являются немеждународными, можно отнести и к межгосударственным.
Все чаще, зарождающиеся как внутренние, многие конфликты характеризуются значительным потенциалом превращения в международные. Мы поддерживаем мнение В.С. Солодченко, Г.В. Алексеева [11, с. 65], М.Ш. Магомедова [7, с. 273-274] о необходимости расширения сферы действия международного гуманитарного права, в частности, норм, закрепляющих особенности правового статуса и механизмы защиты журналистов. Необходимо продолжать работу по закреплению в международных конвенциях и договоренностях фиксации обязательного гарантированного минимума прав журналистов, которые ведут профессиональную деятельность в зоне вооруженных конфликтов различных видов, и ввести норму о недопустимости умаления их прав.

Несмотря на активные усилия международного сообщества, статистика нарушения прав журналистов и убийств, связанных с профессиональной деятельностью в зоне конфликтов, печальна. По данным мониторинга ЮНЕСКО, в мире около 75 \% убийств журналистов произошли по причинам осуществления ими профессиональных обязанностей в зоне вооруженных конфликтов [18, p. 11]. По данным «Комитета по защите журналистов», с 2000 по 2015 г. число журналистов, которые погибли по причинам, достоверно связанным с профессиональной деятельностью, увеличилось в два раза [16]. Таким образом, эффективность правоприменительной практики в исследуемой сфере по-прежнему можно охарактеризовать как низкую. Актуальной является и проблема безнаказанности лиц, совершивших преступления в отношении журналистов. Существующие проблемы неоднократно отмечались в Резолюциях $\mathrm{OOH}$, подчеркивающих безрезультатность усилий правозащитных организаций и международного сообщества по обеспечению прав сотрудников средств массовой информации в зоне вооруженных конфликтов [9]. Не следует забывать, что обеспечение безопасности журналистов и борьба с безнаказанностью виновных в преступлениях против них является обязательной частью международных обязательств государств, принятых для обеспечения условия реализации права на свободу выражения мнений. 


\section{МЕЖДУНАРОДНОЕ ПРАВО И СРАВНИТЕЛЬНОЕ ПРАВОВЕДЕНИЕ}

В связи с усугублением ситуации многочисленные организации по защите интересов журналистов многократно указывали $\mathrm{OOH}$ на необходимость учреждения должности Специального представителя Генерального секретаря по безопасности журналистов [16]. Мы поддерживаем данное предложение, так как только институт специального представительства способствует обеспечению тесного сотрудничества и координации всех заинтересованных в решении данной проблемы сторон, приданию ей политического веса на международном уровне, созданию условий для оперативных и легитимных действий по защите прав журналистов в вооруженных конфликтах.

В современных условиях актуальными проблемами также являются обеспечение условий для беспрепятственной профессиональной деятельности журналистов, разработка механизмов, позволяющих осуществлять профилактику и выявление преступлений и правонарушений как на внутригосударственном, так и на международном уровне.

\section{СПИСОК ЛИТЕРАТУРЫ}

1. Дополнительный протокол к Женевским конвенциям от 12 августа 1949 года, касающийся защиты жертв вооруженных конфликтов немеждународного характера (Протокол II), 9 июня 1977 года // Международное гуманитарное право в документах / Ю. М. Колосов, И. И. Котляров. - М. : Изд-во МНИ международного права, 1996. - С. 408-417.

2. Дорога к правосудию: специальный доклад Комитета по защите журналистов / Э. Уитчелл, М. Гонгадзе [и др.]. - СРЈ, 2014. - 82 с.

3. Женевская конвенция о защите гражданского населения во время войны от 12 августа 1949 года // Международное гуманитарное право в документах / Ю. М. Колосов, И. И. Котляров. - М. : Изд-во МНИ международного права, 1996. - С. 266-333.

4. Ибраева, Г. Ж. Региональные конфликты и средства массовой информации / Г. Ж. Ибраева. Электрон. текстовые дан. - Режим доступа: http:// library.cjes.ru/online $/ ? \mathrm{a}=$ con\&b_id $=19 \& \mathrm{c} \_\mathrm{id}=384$. Загл. с экрана.

5. Иншакова, А. О. Несовпадающее особое мнение научного сообщества с решением большой палаты ЕСПЧ по делу «Кононов против Латвии»: правовые аргументы / А. О. Иншакова // Вестник Волгоградского государственного университета. Серия 5 , Юриспруденция. - 2011. - № 1 (14). - С. 89-98.
6. Котляров, И. И. Международно-правовое регулирование вооруженных конфликтов: основные теоретические проблемы и практика : дис. .... канд. юрид. наук / Котляров Иван Иванович. - М., 2008. - 55 с.

7. Магомедов, М. Ш. Международно-правовое регулирование пределов защиты журналиста во время вооруженного конфликта / М. Ш. Магомедов // Московский журнал международного права. - 2007. - № 4 (68). - С. 273-274.

8. Освещение журналистами экстремальных ситуаций / авт.-сост. Г. Ю. Арапова, С. И. Кузеванова, М. А. Ледовских, Б. Н. Пантелеев. - 2-е изд., испр. и доп. - Воронеж : Элист, 2012. - 160 с.

9. Резолюция Совета ООН по правам человека $\mathrm{A} / \mathrm{HRC} / 21 / \mathrm{L} .6$ «Безопасность журналистов». - Электрон. текстовые дан. - Режим доступа: http:/ap. ohchr.org/documents/sdpage_e.aspx?b=10\&se $=133 \& \mathrm{t}$ $=4$ (дата обращения: 07.02.2016). - Загл. с экрана.

10. Рыжов, А. И. Юридические дефиниции в международном праве (на примере «война», «вооруженный конфликт международного характера», «вооруженный конфликт немеждународного характера») / А. И. Рыжов // Юридическая техника. 2007. - № 1. - С. 129-134.

11. Солодченко, В. С. Международно-правовой статус журналиста в зоне вооруженного конфликта / В. С. Солодченко, Г. В. Алексеев // Российский ежегодник международного права. - 2005. - Спец. вып. - С. 61-69.

12. Тарасова, Л. Н. К дискуссии о правомерности гуманитарной интервенции / Л. Н. Тарасова // Вестник Волгоградского государственного университета. Серия 5, Юриспруденция. - 2011. - № 1 (14). - C. 99-105.

13. Фролова, И. Н. Международные стандарты в области прав человека и их место в системе источников уголовного права / И. Н. Фролова // Актуальные проблемы экономики и права. - 2010. № 1. - C. 172-178.

14. Хенкертс, Ж.-М. Обычное международное гуманитарноеправо:пер. сангл. Т.І.Нормы/Ж.-М. Хенкертс, Л. Досвальд-Бек. - М. : МККК, 2006.-818 с.

15. Prosecutor v. Zejnil Delalić et al., case No. IT96-21-T, Judgement of 16 November 1998, para. 209 ; Prosecutor v. Tihomir Blaškić case, case No. IT-95-14T, Judgement of 3 March 2000, para. 64.

16. Reporters without borders is today publishing its round-up of abuses against journalists in 2014 // PC DEC № 193. - 05.11.1997 (№ 1). - Electronic text data. - Mode of access: http://en.rsf.org/rwbpublishes-2014-round-up-of-16-12-2014,47388.html\# bilan02 (date of access: 07.12.2015). - Title from screen.

17. The role of embedded reporting during the 2003 Iraq War : summary report. - L. : BBC, 2003. -148 p.

18. World trends in freedom of expression and media development-2014. - UNESCO, 2014. - 104 p. 


\section{REFERENCES}

1. Dopolnitelnyy protokol k Zhenevskim konventsiyam ot 12 avgusta 1949 goda, kasayushchiysya zashchity zhertv vooruzhennykh konfliktov nemezhdunarodnogo kharaktera (Protokol II), 9 iyunya 1977 goda [Additional Protocol to the Geneva Conventions of August 12, 1949 Concerning the Protection of Victims of Non-International Armed Conflicts (Protocol II), June 9, 1977]. Kolosov Yu.M., Kotlyarov I.I., eds. Mezhdunarodnoe gumanitarnoe pravo $v$ dokumentakh [International Humanitarian Law in Documents]. Moscow, Izd-vo MNI mezhdunarodnogo prava, 1996, pp. 408-417.

2. Uitchell E., Gongadze M., et al. Doroga $k$ pravosudiyu: spetsialnyy doklad Komiteta po zashchite zhurnalistov [Road to Justice: a Special Report by the Committee on Journalists's Protection]. CPJ, 2014. $82 \mathrm{p}$.

3. Zhenevskaya konventsiya o zashchite grazhdanskogo naseleniya vo vremya voyny ot 12 avgusta 1949 goda [Geneva Convention on the Protection of Civil Population During War of August 12, 1949]. Kolosov Yu.M., Kotlyarov I.I., eds. Mezhdunarodnoe gumanitarnoe pravo $v$ dokumentakh [International Humanitarian Law in Documents]. Moscow, Izd-vo MNI mezhdunarodnogo prava, 1996, pp. 266-333.

4. Ibraeva G.Zh. Regionalnye konflikty $i$ sredstva massovoy informatsii [Regional Conflicts and Mass Media]. Available at: http://library.cjes.ru/online/ $? \mathrm{a}=$ con\&b_id=19\&c_id=384.

5. Inshakova A.O. Nesovpadayushchee osoboe mnenie nauchnogo soobshchestva s resheniem bolshoy palaty ESPCh po delu «Kononov protiv Latvii»: pravovye argument [The Dissenting Opinion of the Scientific Community with the Decision of Large Chamber of the ECHR on the Case "Kononov vs. Latvia": Legal Arguments]. Vestnik Volgogradskogo gosudarstvennogo universiteta. Seriya 5, Yurisprudentsiya [Science Journal of Volgograd State University. Jurisprudence], 2011, vol. 1, no. 5-14, pp. 89-98.

6. Kotlyarov I.I. Mezhdunarodno-pravovoe regulirovanie vooruzhennykh konfliktov: osnovnye teoreticheskie problemy i praktika: dis... kand. yurid. nauk [International Legal Regulation of Armed Conflicts: Main Theoretical Problems and Practice. Cand. jurid. sci. diss.]. Moscow, 2008. 55 p.

7. Magomedov M.Sh. Mezhdunarodnopravovoe regulirovanie predelov zashchity zhurnalista vo vremya vooruzhennogo konflikta [International Legal Regulation of Journalists's Protection During an Armed Conflict]. Moskovskiy zhurnal mezhdunarodnogo prava, 2007, no. 4 (68), pp. 273-274.

8. Arapova G.Yu., Kuzevanova S.I., Ledovskikh M.A., Panteleev B.N. Osveshchenie zhurnalistami ekstremalnykh situatsiy [Coverage of Extreme Situations by Journalists]. Voronezh, Elist Publ., 2012. $160 \mathrm{p}$.

9. Rezolyutsiya Soveta OON po pravam cheloveka A/HRC/21/L.6 "Bezopasnost zhurnalistov» [Resolution of the UN Human Rights Council A/HRC/21/L.6 "The Safety of Journalists"]. Available at: http://ap.ohchr.org/documents/sdpage_ e.aspx $? \mathrm{~b}=10 \& \mathrm{se}=133 \& \mathrm{t}=4$. (accessed February 7 , 2016).

10. Ryzhov A.I. Yuridicheskie definitsii v mezhdunarodnom prave (na primere «voyna», «vooruzhennyy konflikt mezhdunarodnogo kharaktera», «vooruzhennyy konflikt nemezhdunarodnogo kharaktera») [Legal Definitions in International Law (on the Example of Words "War", "International Armed Conflict", "Non-International Armed Conflict")]. Yuridicheskaya tekhnika, 2007, no. 1, pp. 129-134.

11. Solodchenko V.S., Alekseev G.V. Mezhdunarodno-pravovoy status zhurnalista v zone vooruzhennogo konflikta [International Legal Status of Journalist in the Zone of Armed Conflict]. Rossiyskiy ezhegodnik mezhdunarodnogo prava, 2005, special issue, pp. 61-69.

12. Tarasova L.N. K diskussii o pravomernosti gumanitarnoy interventsii [To Discussion on the Legitimacy of Humanitarian Intervention]. Vestnik Volgogradskogo gosudarstvennogo universiteta. Seriya 5, Yurisprudentsiya [Science Journal of Volgograd State University. Jurisprudence], 2011, vol. 1, no. 5-14, pp. 99-105.

13. Frolova I.N. Mezhdunarodnye standarty v oblasti prav cheloveka i ikh mesto $\mathrm{v}$ sisteme istochnikov ugolovnogo prava [International Standards in the Field of Human Rights and Their Place in the System of Criminal Law Sources]. Aktualnye problemy ekonomiki i prava, 2010, no. 1, pp. 172-178.

14. Khenkerts Zh.-M., Dosvald-Bek L. Obychnoe mezhdunarodnoe gumanitarnoe pravo: T. I. Normy [Ordinary International Humanitarian Law: Vol. I. Norms]. Moscow, MKKK Publ., 2006. 818 p.

15. Prosecutor v. Zejnil Delalić et al., case no. IT96-21-T, Judgement of 16 November 1998, para. 209; Prosecutor v. Tihomir Blaškić, case no. IT-95-14-T, Judgement of 3 March 2000, para. 64.

16. Reporters Without Borders is Today Publishing its Round-up of Abuses against Journalists in 2014. RC DEC no. 193, 5 noyabrya 1997 g., Point 1. Available at: http://en.rsf.org/rwb-publishes-2014round-up-of-16-12-2014,47388.html\#bilan02. (accessed December 7, 2015).

17. The Role of Embedded Reporting During the 2003 Iraq War: Summary Report. London, BBC, 2003. $148 \mathrm{p}$.

18. World Trends in Freedom of Expression and Media Development-2014. UNESCO, 2014. 104 p. 


\section{МЕЖДУНАРОДНОЕ ПРАВО И СРАВНИТЕЛЬНОЕ ПРАВОВЕДЕНИЕ}

\section{Information About the Authors}

Hasson Dhiyaa Hasson, Postgraduate Student, the Department of International Law, Peoples' Friendship University of Russia (RUDN - University), Miklukho-Maklaya St., 6, room 368, 117198 Moscow, Russian Federation, bukurujb@mail.ru, dhiyaa@mail.ru.

Evgeny V. Martynenko, Candidate of Juridical Sciences, Associate Professor, the Department of International Law, Peoples' Friendship University of Russia (RUDN - University), Miklukho-Maklaya St., 6, room 368, 117198 Moscow, Russian Federation, emartynenko@mail.ru.

\section{Информация об авторах}

Хассон Дия Хассон, аспирант кафедры международного права, Российский университет дружбы народов, ул. Миклухо-Маклая, 6, каб. 368, 117198 г. Москва, Российская Федерация, bukurujb@mail.ru, dhiyaa@mail.ru.

Евгений Владимирович Мартыненко, кандидат юридических наук, доцент кафедры международного права, Российский университет дружбы народов, ул. Миклухо-Маклая, 6, каб. 368, 117198 г. Москва, Российская Федерация, emartynenko@mail.ru. 